TABLE 4. Economic analysis of early treatment for EAW in the Mojave Desert, Callfornia

\begin{tabular}{|c|c|c|}
\hline $\begin{array}{l}\text { Treatment } \\
\text { date }\end{array}$ & Yield & $\begin{array}{l}\text { First cutting } \\
\text { return/acre }\end{array}$ \\
\hline & tons/acre & $\$$ \\
\hline \multicolumn{3}{|c|}{ 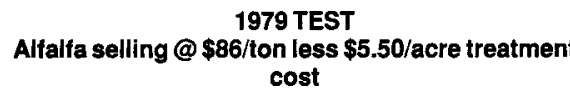 } \\
\hline $\begin{array}{l}\text { Mar } 15 \\
\text { Apr } 2 \\
\text { Check }\end{array}$ & $\begin{array}{l}2.00 \mathrm{a} \\
1.34 \mathrm{~b} \\
1.19 \mathrm{~b}\end{array}$ & $\begin{array}{r}\$ 166.50 \\
\$ 109.74 \\
\$ 96.84\end{array}$ \\
\hline \multicolumn{3}{|c|}{$\begin{array}{c}1987 \text { test } \\
\text { Alfalfa selling@\$110/ton less \$18.02/acre treat- } \\
\text { ment cost }\end{array}$} \\
\hline $\begin{array}{l}\text { Feb } 16 \\
\text { Mar } 2 \\
\text { Mar } 16 \\
\text { Mar } 28 \\
\text { Check }\end{array}$ & $\begin{array}{l}2.04 \mathrm{a} \\
1.95 \mathrm{ab} \\
1.84 \mathrm{bc} \\
1.75 \mathrm{c} \\
1.50 \mathrm{~d}\end{array}$ & $\begin{array}{l}\$ 206.38 \\
\$ 196.48 \\
\$ 184.38 \\
\$ 174.48 \\
\$ 165.00\end{array}$ \\
\hline \multicolumn{3}{|c|}{$\begin{array}{c}1988 \text { test } \\
\text { Alfalfa selling@\$110/ton less } \$ 18.02 / \text { acre treat- } \\
\text { ment cost }\end{array}$} \\
\hline $\begin{array}{l}\text { Feb 16 } \\
\text { Feb 26 } \\
\text { Mar } 5 \\
\text { Mar } 15 \\
\text { Mar 25 } \\
\text { Check }\end{array}$ & $\begin{array}{l}1.99 \mathrm{a} \\
1.87 \mathrm{abc} \\
1.96 \mathrm{ab} \\
1.86 \mathrm{abc} \\
1.70 \mathrm{bc} \\
1.24 \mathrm{~d}\end{array}$ & $\begin{array}{l}\$ 200.88 \\
\$ 187.68 \\
\$ 197.58 \\
\$ 186.58 \\
\$ 168.98 \\
\$ 136.40\end{array}$ \\
\hline
\end{tabular}

NOTE: See table 1 NOTE.

treated on February 16. Similar crop loss was evident in the 1988 test when treatment was delayed until March 25.

Alfalfa stands remain productive in the Mojave Desert for 6 to 8 years and sometimes longer, provided the stand is not severely damaged. More importantly, alfalfa growers are in business to make money. The monetary return from the various Egyptian alfalfa weevil treatment times for the 3 years of the trials is summarized in table 4. Effects of the weevil on the second cutting are not included.

Since there are no effective biological control agents of Egyptian alfalfa weevil, growers have to apply a pesticide or lose a good portion of the crop. Moreover, weevildamaged alfalfa will not sell at a premium price. Our results strongly suggest that chemical treatment for Egyptian alfalfa weevil in the Mojave Desert should be applied soon after the alfalfa regrowth begins and weevil damage is present on the new stems. On a calendar basis, this will vary from one field to another, depending on location, altitude, wind patterns, and winter temperature.

Vernon M. Stern is Professor of Entomology, Department of Entomology, University of California, Riverside, and Steve B. Orloff is HighDesert Farm Advisor, UC Cooperative Extension, Los Angeles and San Bernardino counties. Appreciation is expressed to Gene Nebeker, Junior Peters, and Joe and Ron Harter for providing alfalfa fields and sustaining crop loss in this research.

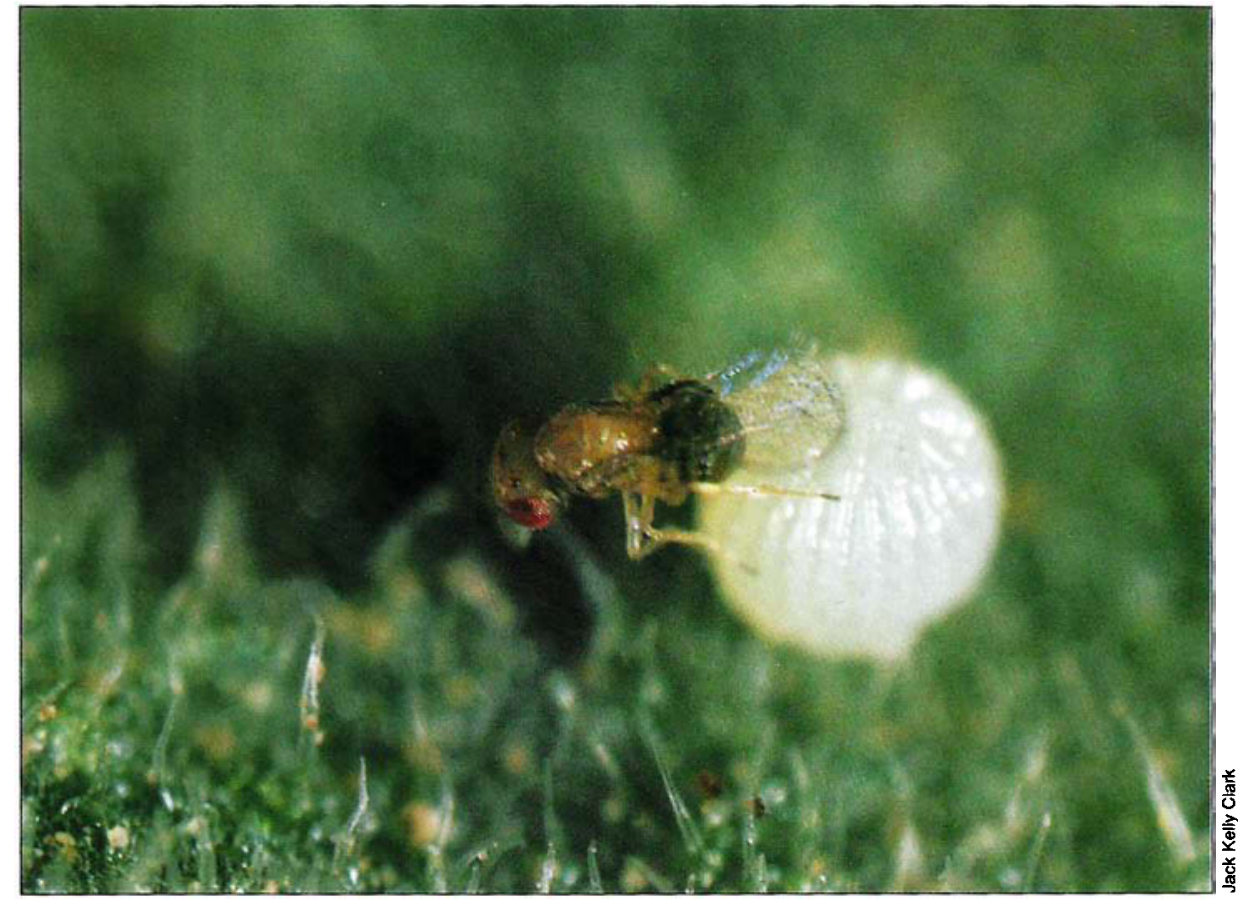

Trichogramma wasp parasitizing tomato fruitworm egg

\title{
Parasitoid helps control fruitworm in Sacramento Valley processing tomatoes
}

\author{
Michael P. Hoffmann a Lloyd T. Wilson a FrankG.Zalom \\ Richard J. Hilton $\square$ Craig V. Weakley
}

\section{Naturally occurring populations of} the parasitic wasp Trichogramma help control the tomato fruitworm in processing tomatoes grown in the Sacramento Valley. Incorporating this factor into the pest management decision-making process should reduce insecticide applications needed to control the pest.

California produces more than $85 \%$ of the processing tomatoes grown in the United States. About $40 \%$ ( 91,000 acres) of these are grown in the Sacramento Valley. The lepidopterous (worm) pests of processing tomatoes in the Sacramento Valley include the tomato fruitworm (Heliothis zea), beet armyworm, (Spodoptera exigua), and the western yellowstriped armyworm, $(S$. praefica). The tomato fruitworm is the most important, because its habit of entering and feeding within tomato fruit reduces crop quality. The cabbage looper (Trichoplusia ni) and hornworms (Manduca spp.) are often present in fields but generally are not economically important.

The integrated pest management (IPM) program for tomatoes includes a sampling procedure and guidelines for treatment based on numbers of worm-damaged fruit and tomato fruitworm eggs. Insecticide applications can then be timed to coincide with egg hatch, when small larvae are most exposed.

The original treatment threshold was based on an assumption that each tomato 


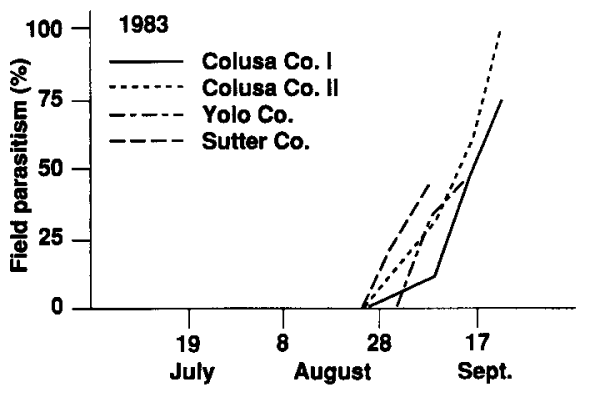

Fig. 1. Parasitism of tomato fruitworm eggs ranged from $46 \%$ to $100 \%$ in four Sacramento Valley fields of commercial processing tomatoes in 1983.

fruitworm egg would produce a larva and cause a predictable amount of damage. In reality, this threshold overestimated potential damage, because various mortality factors were not included.

One such factor was parasitism of eggs by naturally occurring parasitoids. Little information was available on their effect on processing tomatoes in the Sacramento Valley. However, natural populations of egg parasitoids, in particular the parasitic wasp Trichogramma, help control lepidopterous pests of tomatoes and other crops in other regions.

We therefore conducted research in the Sacramento Valley to: (1) determine which parasitoid species were parasitizing the eggs of lepidopterous species in commercial fields of processing tomatoes; (2) quantify the rates of egg parasitism, particularly in tomato fruitworm eggs; (3) if egg parasitism was found to be an important mortality factor, develop a technique to incorporate it into the existing pest management program; and (4) determine if commercial insecticide applications affected the rate of parasitism of tomato fruitworm eggs.

\section{Methods}

We monitored fields of processing tomatoes for 4 years to determine which egg parasitoids were present and their importance in helping control lepidopterous pests. A tomato cultivar trial on theUniversity of California Davis campus was sampled in 1981. Four, seven, and eight commercial fields of processing tomatoes in the Sacramento Valley were sampled for tomato fruitworm, cabbage looper, and hornworm eggs in 1983, 1985, and 1986, respectively.

In 1981, whole tomato plants were examined weekly (July 16 to September 17) for eggs of these three pests. In 1983, the first leaf below each flower cluster on the tomato plant was examined for eggs. From July 12 to harvest, 18 to 30 plants per field were examined each week.

During 1985 and 1986, the first leaf below the highest or second highest flower cluster on each tomato plant was examined. Earlier research identified this leaf as most likely to have tomato fruitworm eggs, and it is the sample unit prescribed by the tomato IPM program. This leaf, however, is not necessarily the optimal location for sampling other lepidopterous species. In 1985 and 1986, 30 leaves were sampled from each of 18 areas per field, for a total of 540 leaves per observation. Occasionally, water stress, crop maturity, or disease resulted in tomato plants with no or few flowers in some sampling areas of the field, so that less than 540 leaves were sampled.

Eggs recorded per species per sample date were pooled across all sampling areas for each field when calculating percent parasitism. Sampling generally started in mid-July and continued until just before harvest. Commercial fields were all lateseason (harvested during mid-August or later) and, consequently, were more likely to have high pest densities and incur more damage.

Parasitized and unparasitized eggs can be distinguished to some extent in the field by their color differences. Tomato fruitworm eggs are white when first laid and develop a reddish brown ring after about a day. If parasitized by Trichogramma, eggs turn solid black in about 4 days. In the field, solid black eggs were considered parasitized; white or cream-colored eggs were recorded as unparasitized. Unparasitized eggs occasionally appear parasitized as hatch nears, because the larval head capsule becomes visible through the thin shell, darkening the upper part of the egg. Close examination with a hand lens may be required to distinguish these from parasitized eggs. We refer to parasitism based on the number of black eggs as "field parasitism."

Because it takes 4 days for a parasitized tomato fruitworm egg to turn black, some of the white eggs in field samples may be parasitized but not recognized as such. Todetermine what percentage of the white eggs observed in the field were parasitized, we collected subsamples of eggs in 1985 and 1986 and returned them to the laboratory. We placed them in small vials or gelatin capsules and monitored the emergence of Trichogramma adults or lepidopterous larvae. We refer to parasitism based on the percentage of white eggs that contained Trichogramma when dissected or from which Trichogramma emerged as "actual" parasitism. Parasitism calculated this way excludes black eggs, which are present in the field several days longer than unparasitized eggs.

TABLE 1. Adjustment of treatment threshold for tomato fruitworm using the number of black and white eggs present in samples of 30 tomato leaves

\begin{tabular}{|c|c|c|c|c|c|c|c|c|c|c|}
\hline \multirow{2}{*}{$\begin{array}{l}\text { Black } \\
\text { eggs }\end{array}$} & \multicolumn{9}{|c|}{ White eggs* } & \multirow[b]{2}{*}{15} \\
\hline & $\overline{4}$ & to & 8 & 9 & 10 & 11 & 12 & 13 & 14 & \\
\hline 1 & - & & - & $T$ & $\mathrm{~T}$ & $\mathrm{~T}$ & $\mathrm{~T}$ & $T$ & $\mathrm{~T}$ & $\mathrm{~T}$ \\
\hline 2 & - & & - & - & - & $\mathrm{T}$ & $\mathrm{T}$ & $T$ & $T$ & $T$ \\
\hline 3 & - & & - & - & - & - & $\mathrm{T}$ & $T$ & $\mathrm{~T}$ & $\mathrm{~T}$ \\
\hline 4 & - & & - & - & - & - & - & $T$ & $\mathrm{~T}$ & $\mathrm{~T}$ \\
\hline 5 & - & & - & - & - & - & - & $\mathrm{T}$ & $\mathrm{T}$ & $\mathrm{T}$ \\
\hline 6 & - & & - & - & - & - & - & $\mathrm{T}$ & $\mathrm{T}$ & $\mathrm{T}$ \\
\hline 7 & - & & - & - & - & - & - & - & $\mathrm{T}$ & $\mathrm{T}$ \\
\hline 8 & - & & - & - & - & - & - & - & $\mathrm{T}$ & $T$ \\
\hline 9 & - & & - & - & - & - & - & - & - & $\mathrm{T}$ \\
\hline 10 & - & & - & - & - & - & - & - & - & $\mathrm{T}$ \\
\hline
\end{tabular}

"Letter " $\mathrm{T}$ " indicates ratio at which treatment is recommended. If no black eggs are recorded, collect and observe white eggs for 48 hours and subtract those that turn black due to parasitism.

TABLE 2. Parasitism of cabbage looper and hornworm eggs in commercial processing tomatoes, Sacramento Valley

\begin{tabular}{|c|c|c|c|c|c|c|}
\hline \multirow{3}{*}{$\begin{array}{l}\text { Insect and } \\
\text { year }\end{array}$} & \multicolumn{6}{|c|}{ Parasitism } \\
\hline & \multicolumn{2}{|c|}{ July } & \multicolumn{2}{|c|}{ August } & \multicolumn{2}{|c|}{ September } \\
\hline & $n^{*}$ & $\%$ & $n$ & $\%$ & $n$ & $\%$ \\
\hline $\begin{array}{l}1981 \text { field } \\
1983 \text { field } \\
1985-86 \text { field } \\
1985-86 \text { actual }^{5}\end{array}$ & $\begin{array}{r}26 \\
109 \\
30 \\
6\end{array}$ & $\begin{array}{l}0 \\
0 \\
0 \\
0\end{array}$ & $\begin{array}{r}181 \\
36 \\
78 \\
63\end{array}$ & $\begin{aligned} 0 \\
0 \\
2.6 \\
30.2\end{aligned}$ & $\begin{array}{r}27 \\
4 \\
6 \\
2\end{array}$ & $\begin{array}{c}0 \\
0 \\
33.3 \\
50.0\end{array}$ \\
\hline $\begin{array}{l}\text { Hornworm } \\
1981 \text { field } \\
1983 \text { field } \\
1985-86 \text { field } \\
1985-86 \text { actual }\end{array}$ & $\begin{array}{r}11 \\
7 \\
2 \\
2\end{array}$ & $\begin{array}{l}0 \\
0 \\
0 \\
0\end{array}$ & $\begin{array}{l}58 \\
18 \\
21 \\
18\end{array}$ & $\begin{array}{c}5.2 \\
0 \\
19.0 \\
55.6\end{array}$ & $\begin{array}{r}75 \\
4 \\
9 \\
5\end{array}$ & $\begin{array}{c}42.7 \\
50.0 \\
0 \\
80.0\end{array}$ \\
\hline
\end{tabular}

" $n$ is the number of eggs recorded during month.

- Field parasitism is the number of black eggs/(black + white eggs) as observed in the field.

s Actual parasitism is the percentage of white eggs parasitized, based on subsample of eggs observed in field. 
During 1981 and 1983, we examined 219 tomato fruitworm eggs in the field. In 1985 and 1986, we observed over 5,000 tomato fruitworm eggs in the field and monitored about $80 \%$ of these in the laboratory. During the 4 years, 497 cabbage looper and 205 hornworm eggs were observed in the field, and 71 and 25 of these, respectively, in the laboratory. Eggs killed during handling were excluded from calculations of parasitism.

\section{Results and discussion}

Parasitoids. A subsample of parasitoids that emerged from lepidopterous eggs were identified. Four species of Trichogramma $(T$. pretiosum, $T$. thalense, $T$. deion and T. brevicapillum) parasitized tomato fruitworm eggs. Trichogramma pretiosum and T. brevicapillum also emerged from hornworm eggs. Identification of the additional Trichogramma specimens is in progress.

Parasitism of tomato fruitworm eggs, based on white and black eggs in the field, was very low in 1981, but only 32 eggs were observed. In 1983, parasitism in four fields ranged from $46 \%$ to $100 \%$ (fig. 1). Actual parasitism (percentage of white eggs parasitized) of tomato fruitworm eggs exceeded $83 \%$ in all fields monitored in 1985 . In five of the eight fields in 1986, actual parasitism exceeded $62 \%$ (fig. 2). Early harvest of two fields in 1986 prevented sampling later in the season when parasitism levels may have been higher.

These results suggest that at least four species of naturally occurring Trichogramma are important in causing tomato fruitworm mortality in late-season fields of commercial processing tomatoes in the Sacramento Valley. We also found that a large percentage of the white eggs observed in the field were parasitized. However, these would be considered viable when sampled by field personnel and included as such in treatment decisions.

According to the current processing tomato pest management protocol, field samplers only record white tomato fruitworm eggs found in samples of 30 tomato leaves per field visit. When four eggs are found, an insecticide application is usually recommended. If both black and white tomato fruitworm eggs were included, the ratio of black to white could be used to estimate the percentage of white eggs (actual parasitism) parasitized.

Figure 3 shows the relationship between the ratio of black to white eggs and actual parasitism in fields before late-season insecticide applications. For example, if a field sampler records 5 black and 10 white eggs (ratio $=0.5$ ), then about $70 \%$ of the white eggs are parasitized, or conversely, only about $30 \%$ or 3 of the 10 white eggs are vi- able. Instead of exceeding the current threshold, this sample would actually be one egg below the threshold. There is variation between the observed data and the line fitted to these data (predicted line), especially at low ratios (fig. 3). However, only when observations fall well below the predicted line is there potential for overestimating actual parasitism. Some of this variability may be associated with the small number of eggs observed on some dates. A range of egg densities and ratios and associated treatment recommendations have been derived from the relationship in figure 3 (table 1).

Black eggs are not always present in the field, however. In 1985 and 1986, they were present on about $45 \%$ of the sampling dates before late-season insecticide applications. They were recorded in all fields at least once. Because late-season tomato fruitworm egg densities can increase rapidly (several-fold in one week) and because a parasitized egg takes 4 days to turn black, some fields may have been treated before many black eggs appeared.

When no black tomato fruitworm eggs are found in field samples of 30 leaves, the alternative procedure to estimate parasitism is to collect the white eggs, place them in a small vial, and keep them at room temperature for at least 48 hours. The number of eggs that turn black (due to parasitism) is subtracted from the number of white eggs collected, and the treatment decision adjusted accordingly. There is time to observe the eggs, since pest control advisers generally wait a few days after recording treatable levels to allow the tomato fruitworm eggs to hatch. Pesticides are applied when most of the larvae are exposed and likely to contact or feed on them. White eggs should be collected throughout the season, and parasitism should be observed even when eggs are not at threshold levels. This procedure would provide continuous information on the effect Trichogramma is having on tomato fruitworm infestations.

Field samples indicated that parasitism of cabbage looper and hornworm eggs was greatest late in the season (table 2). Actual parasitism was consistently higher than field parasitism. As with the tomato fruitworm, this finding demonstrates that estimates of egg parasitism made in the field and counts of white and black eggs may underestimate the total impact of Trichogramma.

We know that $T$. deion and T. pretiosum parasitize eggs of loopers and hornworms, and $T$. thalense parasitizes the cabbage looper. Loopers and hornworms, which are generally of minimal economic importance in processing tomatoes, may therefore be important alternate hosts for Trichogramma.

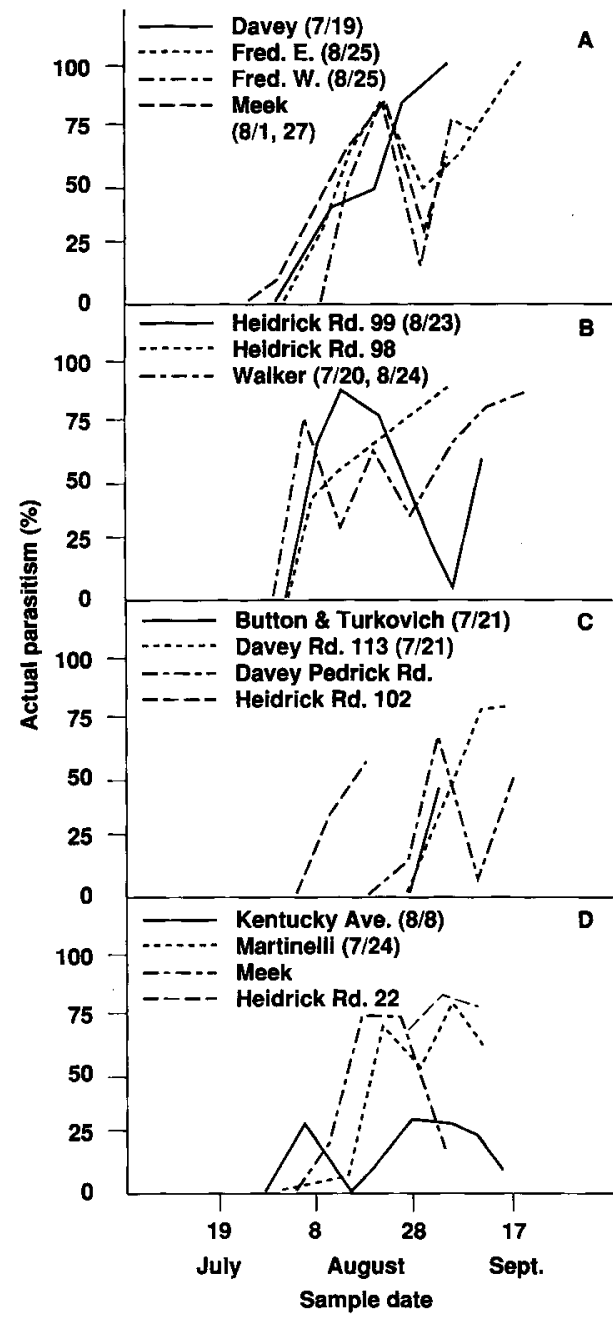

Fig. 2. Actual parasitism of tomato fruitworm eggs exceeded $83 \%$ in all processing tomato fields in $1985(a, b)$ and $62 \%$ in five of eight fields in 1986 (c,d). Insecticide application dates are in parentheses.

In these studies, sampling did not begin until July, so that levels of parasitism of cabbage looper and hornworm eggs before then are unknown. Their importance to early-season buildup of Trichogramma is also unknown.

Fruit quality and treatment threshold. Fruit quality (worm grades) at harvest is of primary concern to processing tomato growers. Excessive worm grades not only can cause harvested loads or fields to be rejected, but also may jeopardize the continuation of grower-processor contracts. Just before harvest in 1985 and 1986 , we examined 168 to 900 mature red fruit in each field for damage caused by lepidopterous larvae. In only one field, which was abandoned (because of market conditions) and not treated with insecticide, was the fruit damage level unacceptably high. This field reached a maximum of 17 white tomato 


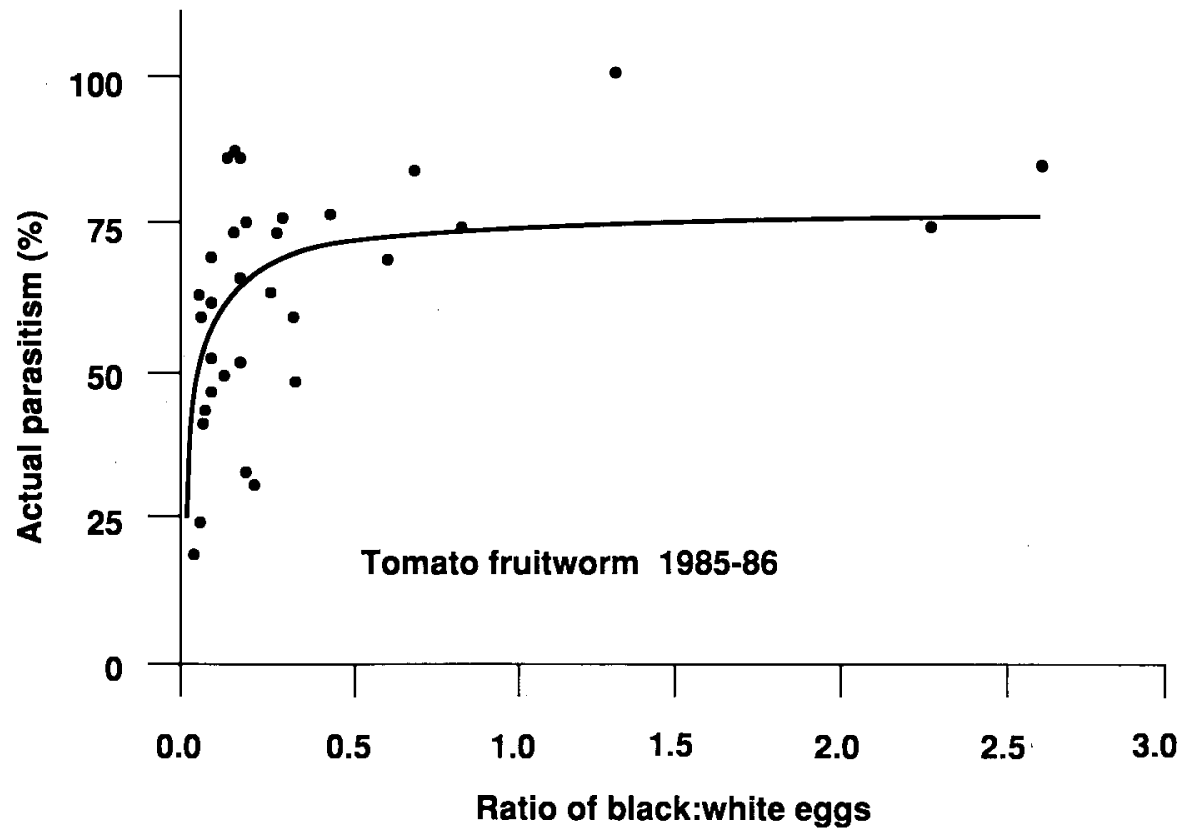

Fig. 3. Relationship between ratio of black to white tomato fruitworm eggs, as observed in the field, and actual parasitism $(\mathrm{Pa})\left[\mathrm{Pa}=76.2 \mathrm{~b}: \mathrm{w} /(0.03+\mathrm{b}: \mathrm{w})\left(\mathrm{r}^{2}=0.93\right)\right]$.

fruitworm eggs per 30 leaves during the season. Three fields had white tomato fruitworm egg counts ranging from 9 to 11 per 30-leaf sample before being treated with insecticide. Of the remaining six fields, three were slightly above the threshold and three were at threshold. Only one field was treated. (Not all fields were managed by the processing tomato IPM program.) These fruit damage samples provided additional evidence that the current tomato fruitworm egg-treatment threshold of four eggs per 30 leaves is conservative and could be raised if Trichogramma are present.

The most convincing support for increasing the tomato fruitworm egg threshold, from the producers' standpoint, comes from fruit damage grades as recorded at official processing tomato grading stations. Fruit damage grades (worm grades) were obtained from 11 of the 15 fields monitored in 1985 and 1986. All loads had acceptable worm damage levels ( $2 \%$ or less); only two loads reached $1 \%$ damage. These grades include damage by all species of lepidopterous larvae, so that actual damage due specifically to tomato fruitworm could have been less than $1 \%$.

Impact of insecticide applications. Other researchers have demonstrated that applications of broad-spectrum insecticides generally decrease parasitism of tomato fruitworm eggs. However, the full impact of insecticides can be difficult to detect because of adult Trichogramma immigrating into previously treated fields and emerging from host eggs parasitized before insecti- cide applications. Parasitoids developing within host eggs can survive applications of several types of insecticides.

In late August 1985, several fields were treated with fenvalarate (Pydrin) or fenvalarate plus methomyl (Lannate or Nudrin) to control tomato fruitworm infestations. These insecticide applications reduced parasitism of tomato fruitworm eggs an average of $46.9 \%$ (S.D.=16.6). During a comparable time period, the percentage of parasitism increased $23.0 \%$ (S.D. $=17.5$ ) in untreated fields (fig. 2a, b). This difference was statistically significant $(\mathrm{P}<0.05)$ based on t-test, where fields were treated as replicates. In most instances, percent parasitism returned to near prespray levels 1 to 2 weeks later (fig. 2).

Although not specifically addressed in these studies, it would be interesting to determine, under more controlled conditions, if early-season insecticide applications for other pests reduce the effectiveness of Trichogramma later in the season. Several fields were treated early in the season in both years for other pests. The Kentucky Avenue field was treated with endosulfan (Thiodan) and carbaryl (Sevin) on August 8, 1986, near the beginning of the late-season tomato fruitworm buildup. Tomato fruitworm egg parasitism in this field was lower than in other fields in 1986 (fig. 2d). This parasitism level may have resulted from the application of carbaryl, which has been shown to be extremely toxic to Trichogramma adults and immature forms on cotton. Carbaryl residues are known to be toxic to adult Trichogramma for a long time.

Because of the decrease in parasitism, the use of the ratio of black to white eggs to predict actual parasitism after insecticide applications may be inappropriate. In addition, several unknown factors, such as the death of adult tomato fruitworms, adult Trichogramma, and developing Trichogramma within host eggs, may affect this relationship. However, normally only one insecticide application is made for late-season tomato fruitworm control, and it is usually the last application before harvest.

\section{Conclusions}

The egg parasitoid Trichogramma appears to be an important cause of tomato fruitworm mortality in late-season processing tomatoes grown in the Sacramento Valley. Its importance in other processing tomato production areas of California is unknown but seems worthy of investigation. Incorporation of tomato fruitworm egg parasitism into the current treatment threshold has the potential to reduce the number of insecticide applications required.

Although our results are based on a sizable data base, factors such as early-season or multiple applications of insecticides, variations in surrounding agricultural or natural habitats, crop growth and development, tomato variety, and interactions among these factors may influence the abundance or effectiveness of Trichogramma. Field demonstration and validation of the modified processing tomato IPM program therefore are required over a range of agronomic conditions and using a more practical sample size. This validation began in 1989 and will continue this year in selected Sacramento Valley locations.

Michael P. Hoffmann is Staff Research Associate, and Lloyd T. Wilson is Professor, Department of Entomology, University of California, Davis; Frank G. Zalom is Integrated Pest Management Specialist and Extension Entomologist, UC Davis; Richard J. Hilton is Research Assistant, Southern Oregon Experiment Station, Medford, Oregon; and Craig V. Weakley is former Farm Advisor, UC Cooperative Extension, Sutter-Yuba County.

The authors acknowledge the assistance of Earl Oatman and Gary Platner, UC Riverside, for identifying Trichogramma specimens, the various growers for use of their fields, and $E$. Chin, L. Hesler, G. Routh, S. Klienhaus, and D. Jones who helped in the field and laboratory. This research was supported in part by the UC Statewide Integrated Pest Management Project. Implementation and validation of the modified processing tomato IPM program is being supported by the California Energy Commission. 